\title{
Work, Insecurity, and Social Justice
}

\author{
DIANE-GABRIELLE TREMBLAY
}

Télé-université de l’Université du Québec à Montréal, Montréal, Canada

This issue on Work, Insecurity, and Social Justice appears very timely, given the present economic crisis, in the aftermath of the financial crisis of 2008-9, and constitutes an important contribution to the debate on this theme. Indeed, over recent decades, work has become less and less secure for many groups (less educated, some aging workers, some women, etc.) and income and economic insecurity have moved high on the agenda of individual and social preoccupations.

Despite the existence of workers with more or less stable jobs, and despite some labour regulations or collective agreements favouring job stability, slow growth periods and repeated crises in the 1980s, 1990s, and again in 2008-9 have resulted in workforce rationalization and layoffs, long-term unemployment, and a reduction in the coverage of as well as level of employment insurance benefits for jobless people. Today only about one out of every two workers is eligible for employment insurance, and in the resource-dependent regions of Canada, where unemployment is higher and long periods of unemployment are more frequent, many workers end up excluded from the employment insurance regime and must rely on social assistance regimes. Furthermore, available jobs are often precarious and poorly paid, which leads to lower benefits while many aging workers are altogether excluded from employment when companies are confronted with difficult times.

In the current economic environment, companies are in an endless search for improved competitiveness and productivity, which often results in demands for flexibility, diversified types of employment, changing work shifts, and ultimately, insecurity for workers. Globalization and the international division of labour have contributed to the displacement of both investment and jobs to developing countries, which leads to an increased feeling of job insecurity for many groups (Lowe et al., 1999), potentially more so for those entering the labour market (youth) and those about to leave (aging workers). Employment insecurity is partly a subjective notion; something an individual feels given his or her job situation and the overall economic situation. Job insecurity, however, can lead to income insecurity and economic insecurity, and this is, of course, a very difficult situation. 
In the North American context in particular, where social benefits are often not as high as in many European countries, especially the Nordic countries, economic insecurity can lead to important issues of social justice (Freyssinet, 2003). Indeed, aging workers in Canada, for example, have much lower benefits than those found in Belgium. This can translate into an important issue of social justice, since some individuals may have worked hard all of their lives, but still find themselves in a situation of poverty at the end of their active career. This is, of course, only one view on the relations between work, insecurity, and social justice.

In recent years, there has been debate regarding the meaning of the concepts of security and insecurity itself, with some authors indicating that this is a relative concept whose meaning changes over time. According to Standing (1999, p. 37), security involves a sense of well-being or control, or mastery over one's activities and development, as well as the enjoyment of a certain amount of self-esteem. Inversely, insecurity involves anxiety and uncertainty (Standing, 1999). Collective security can also be distinguished from other forms of security or insecurity. Again, as per Standing (1999, p. 37), collective (or societal) security could be seen as the need to identify with or belong to a group and typically to exercise control over the behaviour of others or to limit their control. Security arises from multiple forms of identity, such as class, occupation, and community membership (Standing, 1999), to which we would add territorial belonging (Fontan, Klein, \& Tremblay, 2005a, 2005b), which are also sources of social identity, and therefore, a certain level of security.

The company or employer can also be considered a source of security, so it is therefore possible to refer to a certain amount of "company security" such as that found within a Japanese company which generally ensured employees a long term job (Tremblay \& Rolland, 2000). There is also individual security; a person's curriculum vitae, skills, and union membership can provide a feeling of personal security (Standing, 1999, p. 37).

Another question has arisen in research: how can insecurity and security be measured? This is a particularly complex issue which has been the subject of relatively little study. Dasgupta (2001, p. 9) indicates that there are both objective and subjective measures. Objective measures are interesting but limited: unemployment rates, average length of employment vs. unemployment, fixed term contracts vs. indefinite employment, skill transferability, etc. These constitute individual measures of the likelihood that given individuals will maintain ongoing employment, stability, and security. There are also contractual measures, such as the rate of non-standard jobs or job status (Vosko, Zukewich, \& Cranford, 2003), and institutional measures such as legal protection and collective agreements (Dasgupta, 2001, p. 9). As well, there are subjective measures. These may relate to the feeling that one's permanence in employment is guaranteed by the company, as in Japan, or by society and public employment policy, such as in Sweden. In order to assess an individual's relative insecurity or security, the following measures would be of interest: the likelihood of losing one's job, the likelihood of finding another, the value of the current job, and the value of the future job or period of unemployment (Dasgupta, 2001, p. 9). Therefore, we may conclude that insecurity is related to the perception of risk and this perception may vary from one person to another and in different contexts. 
In the context of mass production and large organizations (Fordism), the stability of employees was considered to be a desirable standard for industrial society. The development of trade unionism and the seniority standard contributed to making it expensive for a person to quit his or her job, which tended to favour job stability and the non-mobility of employees. We might wonder why the regulation of the job market occurred. In fact, historically speaking, employment standards, unionization, and unemployment insurance came about as a result of workers' struggles, as a way to compensate for workers' weaker power, but also to ensure stable labour supply for companies who wanted to counter chronic labour instability among farm workers at the beginning of the industrial era. Over the years, income security became associated with the welfare state. However, benefits were only for full-time workers while women were frequently dependent on the family benefit coverage of their spouses (Tremblay, 2008).

In light of the reservations set out about the importance of the labour market as the source of rights, insurance, and income, certain questions arise such as whether job security is still important today, and if so, why, for whom (an issue of social justice), and how.

From the point of view of employers, job security is a constraint on efficiency and flexibility in adjusting production. Publications of the OECD have shown an inverse relationship between job flexibility and job security. Further, a study of several European countries showed that economic slowdowns always relaunch the debate about labour flexibility, precarious forms of employment and wage reductions (Freyssinet, 2003). Some, especially employers, raise the notion that workers should adapt to having less security. However, this raises an issue of social justice, since not all need to adapt to this.

In support of job security, some defend the idea of job security as the main source of economic security, and thus criticize the restrictions imposed on the employment insurance regime several years ago in Canada. Job security is considered important for the well-being of workers and their families, as well as being seen as favouring macro-economic stability. Furthermore, it appears that flexibility and wage reductions do not necessarily translate into job creation, contrarily to orthodox economic theory's claims (Freyssinet, 2003).

There are other avenues to economic security and possibly to social justice, and some theorists defend the concept of a guaranteed or citizen's income. While flexibility is necessary, and some consider that job protection works against flexibility, a citizen's income, or minimum guaranteed income, could possibly offer some form of economic security and provide some degree of social justice. Some writers indeed believe that this would simultaneously ensure social justice and efficiency (Standing, 1999, p.184).

However, this position is contested by many. It overlooks the non-financial advantages of work, including participation in social life, self-esteem, and personal development. Other critics hold that the cost of providing such a citizen's income at an appropriate level would be extremely high, and that a true minimum income is more realistic. Finally, it is argued that the stigma attached to social assistance would not necessarily disappear by just changing the name of the program, even though some believe that a "citizenship" income, considered the right of every citizen, might change people's perspective (Standing, 1999). This remains an issue of debate in relation to social justice and economic security. 
In this issue, two papers deal with end of career and retirement issues, since this is a period of work life which often translates into income or economic insecurity and raises many issues of social justice. The difference between retirement schemes, which may seem normal to the nationals of different countries such as Canada and Belgium, raises the issue of social justice. Indeed, public retirement schemes are apparently more generous in Belgium and more workers can manage to retire early and live decently, which is not the case for many Canadians, who need to work later, and even return to work in some cases, especially in the aftermath of an economic and financial crisis such as that which came upon us in 2008-2009. This crisis will surely have effects on unemployment, exclusion, economic insecurity and social justice over the next decade.

The first paper, by Nathalie Burnay, deals precisely with what happens to older workers in a changing social policy context. The author first reminds us that in comparison with other European countries, as well as many North American or Asian countries, the employment rate of older workers in Belgium is rather low. In fact, Burnay indicates that there had been a trend of decreasing participation in the labour market for workers over 55. In Belgium in 1960, 85\% of men aged 55 to 59 years were active while in 1980, it had decreased to 74 percent and in 1997 the proportion further decreased to 49 percent, a sharp decline. As for women, the author indicates that participation has been very low until the late nineties: about 20 percent for women 55 to 59 years of age, and approximately five percent for women aged 60 to 64 . The proportions reached 31 and 9 percent respectively in 2005, which is still quite below that observed in many other zones, including Canada, where participation rates are much higher.

Burnay reminds us that international organizations have been quite preoccupied about the viability of pensions systems. In Belgium, as in the European Union, the government decided to introduce a series of measures in the early 2000s aimed at encouraging older people to remain in or to re-enter the labour market. The author indicates that in more recent years different factors have led policy makers to reevaluate this policy since it has proved somewhat more difficult than expected to keep people in employment. In such a context, the balance between public policies, trade unions and older workers appears to be disruptive. The paper addresses this challenge thus: the author presents research which sheds light on the impact on workers and discusses the results of this changing social policy pattern in terms of well-being and intention to leave the labour market.

The author reminds us that from the perspective of New Institutionalism early departure from the labour market needs to be understood not simply as a personal choice but rather as a public policy question. She also reminds us that it is the "social benefits" system that encourages particular behaviour in individuals by offering or withdrawing employment opportunities for those over 50, as has been shown in the work by Guillemard, amongst others. The author mentions that the Belgian social protection policies reflect the continental model (a combination of state, private, semi-private, parastatal and NGOs that provide benefits) where the generous unemployment benefits coexists with many possibilities of early withdrawal from the labour market and very limited systems which encourage and integrate the older employee, and this of course has an impact on the attitudes and preferences of aging workers. Indeed, it appears that older workers are condemned to inactivity at the end 
of their careers and that early retirements are quite numerous, a trend which is difficult to change after some time of functioning in this manner. While many consider the possibility of early retirement to be an issue of social justice, it is clear that the public retirement schemes are creating a heavy burden for the State budget, and this is an issue in many countries today, but maybe more so in Belgium because of its many rather generous schemes.

Burnay's paper addresses the important issue of well-being at the age of retirement, as well as the intentions of older workers to retire and sets all of this in the context of changing policies in order to show how these policies influence the attitudes and preferences of workers, given their impact on income and economic security.

Her paper indicates that public policy developed since the 1980s in France as in Belgium has fundamentally changed the view of retirement in society as well as the associated models or norms. Because of this, alongside the then established system, new approaches are now seen as equally legitimate. The author indicates that this is not sufficient to explain the important movement towards early retirement in Belgium. According to Burnay, other variables intervene, particularly other normative elements such as self realization, personal growth, and the need to do something "different" in life. These elements are quite interesting and the analysis presented here helps us to better understand an important societal change: it appears that "the individual no longer expresses their individuality through only one facet of their life but compose elements and facets of their life into a whole through various levels of symbolic participation.” All of these elements make it possible to keep a certain distance as regards work and professional investment or other dimensions of self realization. On the basis of Burnay's paper, the end of one's career is seen as a special period of life in which individuals can reassert or redefine their identity with other forms of activity, either within the family circle or outside it, with volunteer work for example. The "older unemployed" status established in the 1980s in Belgium has clearly contributed largely to the well-being of this specific category of unemployed people, and this is clearly viewed as an element of social justice for the workers concerned. It is, therefore, difficult for the State to go back on these advantages which people apparently enjoy, in relation to early retirement. Burnay's paper also shows that early retirement is not only the result of a desire to escape, and thus leads to a multidimensional and very interesting view on end of careers in the labour market, work, economic security, and self-realization.

In the paper by Tremblay and Genin, the question of how to support older workers who want, or need, to stay longer in employment in order to have decent incomes is addressed. This issue is of great importance, especially from a point of view of social justice with regards to income, considering the fact that public retirement schemes in Canada offer limited income and that many have lost money in their retirement funds in recent years (due to the financial crisis and, sometimes, poor management of these funds including fraud in some cases). The challenges faced by organizations and governments are unprecedented. The demographic evolutions most industrialized countries are facing question the traditional tripartite model of education-workretirement, according to which these three phases are found in succession, with little or no overlap. Indeed, continuing education is needed more and more to maintain the competences of workers throughout their work life. Moreover, retirement can represent a period of time nearly equal to work life. The cost of this "expanded" 
retirement is judged unacceptable by many governments, leading to the question of how to encourage older workers who want to stay longer in employment. Interesting conclusions can be drawn from this paper with regard to these challenges which concern retirement income and social justice.

First of all, the authors show that perception about retirement appears more or less unchanged over the years and remains very positive. Consequently, one of the barriers to the employment of older workers may be the image of retirement itself since it is still perceived as a gift or a right, which is, once again, a social justice issue. However, if the right to retire can be seen as an issue of social justice, the right to a decent retirement income should be as well. Unfortunately, this is not the case for many. While the paper does not address the financial dimension, it is known that up to $30 \%$ of retirees return to the labour market, many for lack of sufficient funds at retirement. This number may increase in the aftermath of the present financial and economic crisis.

The research also shows that the perception of retirement contrasts with the perception of age. Indeed, a large majority of respondents do believe one can perform quality work after the age of 65 but, nevertheless, many appear to want to retire. This result questions work in itself. The research also shows that forcing people to stay longer in the labour market is a largely unpopular measure. Consequently, governments and organizations should probably adopt a more voluntary approach; hence the importance of the evaluation of the different options to encourage older workers to stay longer in employment, since they vary from one professional category and sector to another.

The results highlight the importance of the sector and type of job in the measures or incentives that could encourage older workers to stay longer in employment. Governments and organizations, therefore, should adopt a contingent approach in order to ensure social justice; i.e., all incentives do not necessarily fit all jobs or all sectors, and it may be unjust to force people who have worked very hard, in difficult sectors, to go on working in difficult conditions, while white collar and professionals or managers may see an extended work life as a positive.

This paper also indicates that among the measures that could support older workers who want to stay longer in employment, the progressive reduction of their working time appears the most attractive option. Such an approach represents an important breach in the traditional tripartite model. Indeed, it would inaugurate a new period of time between work life and total retirement. Organizations and government should then develop new systems (in terms of social security or laws) to institutionalize this period of time so that older workers can draw advantages from it without losing the benefits of their retirement, thus ensuring social justice between the various categories of workers.

The paper by Cloutier, Bernard, and Tremblay addresses the issue of social justice from a gendered perspective. It analyses the evolution of men and women's work over a decade (1997-2007), on the basis of Statistics Canada labour force survey. The authors show that the significant increase in the presence of women on the labour market is one of the most important events to have occurred over the last few decades on the issue of work, economic security, and social justice. Job feminization has grown to become a regular feature in most OECD countries and it is thus important to analyze how exactly women have gained their place in the labour 
market, whether it is with more precarious jobs, as was often said in the past, or whether they have accessed the same economic security (same wages and job stability) as men, which would mean that social justice has been attained.

The authors show that, unfortunately, this is not necessarily the case. The massive integration of women into the labour market has translated itself into very different forms of hiring, of jobs, and in working conditions that often tend to increase gender inequality, and thus, social justice between men and women. Even where differences between wage earnings of men and women have strongly decreased in terms of their respective numbers, and this may appear to favour better social justice for women, some indicators also uncover a degradation with respect to job quality of some subgroups. Indeed, female employees fare less well than their male counterparts. Women often hold less lucrative jobs, are more often confined to part-time work against their will or to short-term employment, and are given fewer opportunities to deploy and establish their skills because they are given jobs and assignments that require little, if any, proficiency or aptitude. Persistent gender inequality clearly wears more than one mask; it is not related only to access to employment and to wages, and may conceal true social injustice.

Although they have gained equal footing with men in their level of schooling (Statistics Canada, 2006) and filled the education gap, women apparently still cannot achieve their full potential and access complete socioeconomic independence in less prominent professional occupation or employment status; women are more likely to depend on a spouse's or on someone else's immediate support, financially or otherwise. Gender disparity, however, is not limited to the labour market: there are acute gender issues as well in the division and sharing of family responsibilities and these are highlighted in the paper. The uneven distribution of domestic and professional work between men and women implies that women, although they are part of the workforce, will assume responsibility for more family tasks than men and this apparently has an impact on the types of jobs that many will have access to, thus creating some form of injustice in regard to men's situation; on the other hand, men shoulder more responsibility for financial resources through work in the paid labour market. Actually, both trends reinforce each other in maintaining women in a situation that is less interesting in both spheres, that is the private-home or family_-sphere and the public, paid work sphere.

The paper presents a very detailed analysis of the way in which work quality has evolved for women and for men in Québec over the last decade and proposes a new multidimensional typology that could be used to analyze the situation in various other countries, on the basis of data available in the Labour Force Survey. This paper represents a contribution to the research being done on "quality of work" all over the globe at present and also contributes to the reflection on economic insecurity and social justice in relation to employment and conditions of work.

In Morel's paper, the main concern is with economic insecurity, a theme which is very high on the agenda in times of high unemployment, and with the need of a theoretical shift in economics for analysing and devising efficient and innovative policy reforms to combat employment insecurity and, thus, economic insecurity. It is clear in periods of economic crisis and unemployment that social justice is questioned. Indeed, the persons excluded from employment are the last ones to have entered the labour market, the less educated, the oldest or youngest, depending on a firm's strategy or options. In any case, it brings forward issues of social justice. 
Morel considers that the analysis of the crisis and its impact must be questioned and that mainstream economics is unable to provide appropriate theorizing about economic phenomena, including economic insecurity. It thus appears important turn to economic theories which radically question the dominant paradigm in economics. John Rogers Commons's institutionalist theory is proposed here as a substitute.

The author highlights the fact that the inadequacy of mainstream economics, or of neoclassical economics, is a fact insufficiently known. She mentions that this approach generates an economic analysis on the basis of concepts and models disconnected from the real-world economy and because of this fact it cannot provide appropriate theorizing about key factors of economic life, nor strategic economic issues. The author indicates that it is essential to proceed to a theoretical reconstruction in economics. What is at stake is all the more important in the present economic context, since it is our ability to understand economic insecurity in all its complexity, as well as to design appropriate solutions to it by means of innovative analysis of labour and employment issues.

First, the author of this paper outlines the distinctive character of Commons's institutionalist theory by presenting some of its crucial methodological differences with neoclassical economics. Commons is one of the founders of what is called the original institutionalism, which was developed at the end of the 19th century and continued until the 1940s in the United States. Commons's theory, whose relevance to the world today is being rediscovered, provides a coherent interdisciplinary conception of economic facts, grounded in their cultural context, in which economics, law and ethics are reconciled.

The author then explains how economic insecurity is conceptualized as an "instituted" process with this theory of institution. A better mastery of this specific school of thought in economics appears to help solve the problems met by mainstream economics by proposing a real theoretical alternative for the development of a truly evolutionary, trans-disciplinary, and ethical economic theory. The author thus presents a very stimulating reflection in a context where every government, party, or organization is searching for means to bring us out of the economic crisis while trying not to have such a situation reproduce itself too quickly. The author considers that the current worldwide crisis characterizes itself by an overdeveloped sophisticated financial sector which is clearly detrimental to sustained employment, due to the fact that labour has become the main adjustment variable in economic processes. If this crisis, which, according to the author "has now degenerated in many countries into a crisis of employment, jeopardizing the economic status of important segments of the population and primarily those who are the most vulnerable-is a turning point for the goal of achieving decent work and social justice, it is clear that platforms of action should be rooted in a sound theoretical basis." It is in this perspective that the author presents Commons's institutionalism as an economic theory that could play an important role in the social sciences. The general thrust of the paper is thus to demonstrate that Commonsian institutionalism represents a real theoretical alternative to mainstream economics for the development of a truly evolutionary, trans-disciplinary, and ethical economic theory that could contribute positively to less economic insecurity and more social justice.

Studies in Social Justice, Volume 3, Issue 2, 2009 
All four papers thus contribute to important insights on the issue of economic insecurity and social justice. The last paper does so from a more theoretical perspective, engaging in discussion on the right to work and the right to a decent income as a basic issue of social justice, thus answering Standing's proposal (1999) of citizenship income, while the three others address the situation of specific categories of workers, namely aging workers in the first two cases, and women versus men in the third. As mentioned above, the specificity of the North-American context for aging workers is that they are expected to ensure their economic security largely on their own. In this context, aspirations to prolong working life may appear, but as we say, these aspirations appear to be associated to a demand for more flexibility at the end of the life course. The situation in Belgium is different and the paper shows that policies have an important impact on the attitudes and preferences of workers, given their impact on income and economic security. It also shows that it may be difficult to change policies once workers have organized on the basis of specific policies, for example more generous benefits in a situation of unemployment, as is the case in Belgium. In Canada, social benefits are often not as high as is the case in many European countries, especially the Nordic countries; economic insecurity can lead to important issues of social justice. But age is not the only dimension to be taken into account and one paper shows that a gendered analysis brings forth interesting elements. In Québec, it appears that women's employment situation has improved and is closer to that of men in general. However, this situation also highlights the importance of detailed analyses of various groups, since the situation varies widely, and low levels of education still bear a cost in terms of economic insecurity. All these issues lead to important questions in terms of social justice: how to ensure more social justice among various groups in the labour market and how can more justice be ensured through policy? All the issues of insecurity and social justice could not be covered in so few articles, but the articles in this issue do lead to important questions that encourage further research on the relations between work, insecurity, and social justice.

The question, thus, appears to remain open still: how to ensure simultaneously economic security, social justice, and efficiency? (Standing, 1999; Dasgupta, 2001).

The papers on aging workers highlight the importance of the non-financial advantages of work, including participation in social life, self-esteem, and personal development, which explains why some workers want to go on working past retirement age for reasons other than economic security. This however raises a social justice issue, since not all workers can work at a later age; work is more physically difficult for manufacturing workers than white collar and often leads to an accelerated biological aging process. Also, as mentioned previously, the stigma attached to social assistance still remains and this is why economic security needs to be addressed and orthodox economics and neoliberal views questioned (see EspingAnderson, 1985 and Chapon \& Euzéby, 2002, on the evolution of social models and the market). This issue of retirement and the end of one's career remains an object of debate in relation to social justice and economic security; the present economic crisis has questioned the neoliberal orthodoxy, many wonder whether our governments and leaders will have the courage to question dominant economic dogma and try to ensure social justice and economic security.

The papers presented here cannot address all of the many dimensions of insecurity and social justice. They do make a contribution, however, to the debate on issues of 
work and economic insecurity and they relate to social justice inasmuch as the right to work and the right to a decent income are at the basis of the issues dealt with in all the papers. The papers thus constitute an important contribution to advancing the debate on the meaning of insecurity, on the dimensions to be studied, and on ways to resolve the situation of insecurity, while respecting social justice issues.

\section{References}

Chapon, S., \& Euzéby, C. (2002). Vers une convergence des modèles sociaux européens? Revue internationale de sécurité sociale, 55(2), 49-71.

Dasgupta, S. (2001). Employment security: Conceptual and statistical issues. Geneva: International Labour Office.

Esping-Anderson, G. (1985). Politics against markets: The social democratic road to power. Princeton: Princeton University Press.

Fontan, J.-M., Klein, J.-L., \& Tremblay, D.-G. (2005a). Collective action in local development: The case of Angus Technopole in Montreal, Canadian Journal of Urban Research, 13(2), 317-336.

Fontan, J.-M., Klein, J.-L. \& Tremblay, D.-G. (2005b). Innovation sociale et reconversion économique. Le cas de Montréal. Paris: L'Harmattan.

Freyssinet, J. (2003). Les trois inflexions des politiques de l'emploi. Alternatives économiques, 210, 38-45.

Lowe, G., Schellenberg, G., \& Davidman, K. (1999). Re-thinking employment relationships. (CPRN Discussion Paper no. W-5.) Ottawa: Canadian Policy Research Network.

Paugam, S. (1998). Le revenu minimum d'insertion en France après six ans: un bilan contrasté. Intervencions économiques, 28, 21-45. Retrieved from

www.teluq.uquebec.ca/interventionseconomiques

Standing, G. (1999). Global labour flexibility: Seeking distributive justice. London: Palgrave.

Statistics Canada, (2006). Chapter 4: Education, Women in Canada: A gender-based statistical report (5th ed.) (p. 89-97), (Catalogue No. 89-503-XPE). Ottawa, ON: Statistics Canada.

Tremblay, D.-G. (2008). Precarious work and the labour market. In D. Raphael (Ed.), Social determinants of health: Canadian perspectives (pp. 75-87). Toronto: CSPI Press.

Tremblay, D.-G. \& Rolland, D. (2000). Labour regime and industrialisation in the knowledge economy: The Japanese model and its possible hybridisation in other countries. Labour and Management in Development Journal, 1(7), 1-20.

Vosko, L. F., Zukewich, N., \& Cranford, C. (2003, October) Le travail précaire: une nouvelle typologie de l'emploi. L'emploi et le revenu en perspective, 4(10), 40-51. 